\title{
APROKSIMASI DISTRIBUSI WAKTU HIDUP YANG AKAN DATANG
}

(Aproximations of the Future Lifetime Distribution)

\author{
THOMAS PENTURY ${ }^{1}$, RUDY WOLTER MATAKUPAN ${ }^{2}$, LEXY JANZEN SINAY $^{3}$ \\ ${ }^{I}$ Guru Besar Jurusan Matematika FMIPA UNPATTI \\ ${ }^{2,3}$ Staf Jurusan Matematika FMIPA UNPATTI \\ Jl. Ir. M. Putuhena, Kampus Unpatti, Poka-Ambon \\ e-mail: thomypentury@yahoo.com, rwmatakupan@yahoo.com, lexyjz@gmail.com
}

\begin{abstract}
This paper give an analitical technique to approximate future lifetime distributions. Approximations of the future lifetime distribution based on the shifted Jacobi polynomials, and it yielded the sequences of a exponentials combination. The results of approximations of the future lifetime distribution in this cases study based on Makeham's Law. It is very accurate in the case study.
\end{abstract}

Keywords: approximations, future lifetime distribution, shifted Jacobi polynomials, exponentials combination, Makeham's law

\section{PENDAHULUAN}

Dalam matematika dan statistika, bentuk eksponensial sangat penting dalam penerapannya. Secara khusus, bentuk eksponensial digunakan dalam membentuk fungsi-fungsi khusus untuk menentukan suatu distribusi peluang. Salah satu distribusi peluang yang menggunakan bentuk eksponensial adalah distribusi eksponensial. Distribusi ini memberikan suatu kemudahan dalam berbagai penghitungan.

Penulisan ini memberikan suatu cara untuk mengaproksimasi distribusi peluang dari suatu kombinasi eksponensial. Dengan demikian, masalah yang dikemukakan dalam penulisan ini adalah mengkonstruksi suatu bentuk aproksimasi distribusi waktu hidup yang akan datang (future lifetime) ke dalam bentuk kombinasi eksponensial dan kemudian memperlihatkan keakuratan dari hasil-hasil aproksimasi tersebut secara numerik.

\section{TINJAUAN PUSTAKA}

Pada umumnya bentuk dari kombinasi eksponensial merupakan suatu bentuk kombinasi dari fungsi kepadatan peluang distribusi eksponensial. Secara numerik bentuk kombinasi eksponesial tersebut memiliki kemudahan untuk diterapkan. Hal ini dikarenakan distribusi eksponensial memberikan suatu penghitungan yang sangat sederhana, sehingga mudah untuk dapat diaplikasikan ke berbagai bidang seperti teori resiko, teori antrian, teori keuangan, teori aktuaria, dan lain-lain. Salah satu sifat penting dari kombinasi eksponensial adalah suatu bentuk yang dense dalam himpunan distribusi peluang atas $[0, \infty)$.

Bentuk kombinasi eksponensial dari aproksimasi distribusi peluang dapat dibentuk dengan berbagai metode. Suatu metode aproksimasi distribusi peluang dengan menggunakan sifat-sifat dari polinomial Jacobi merupakan sesuatu bentuk yang konstruktif untuk mengaproksimasi distribusi peluang. Hasil yang diperoleh dari aproksimasi distribusi peluang ini merupakan suatu fungsi distribusi yang terdiri atas barisan-barisan yang berbentuk kombinasi eksponensial, yang mana barisanbarisan tersebut merupakan barisan-barisan yang konvergen. (Dufresne, 2006)

Selain ulasan beberapa pustaka mengenai penulisan ini, pada bagian ini akan diberikan beberapa simbol dan teori-teori dasar yang akan digunakan dalam pembahasan. Berikut ini akan diberikan definisi dari beberapa fungsi khusus. Sebelumnya, simbol Pochhammer untuk suatu bilangan $a$ dinotasikan dengan $(a)_{n}$, didefinisikan seperti berikut,

$$
(a)_{0}=1,(a)_{n}=a(a+1) \cdots(a+n-1), n=1,2, \ldots .
$$

Dengan demikian, fungsi hipergeometri Gauss yang dinotasikan dengan ${ }_{2} F_{1}(\bullet, \bullet, \bullet ; \bullet)$, dapat didefinisikan seperti berikut, 


$$
\begin{aligned}
{ }_{2} F_{1}(a, b, c ; z) & =\frac{\Gamma(c)}{\Gamma(b) \Gamma(c-b)} \\
& \int_{0}^{1}(1-z t)^{-a} t^{b-1}(1-t)^{c-b-1} d t \\
& =\sum_{n=0}^{\infty} \frac{(a)_{n}(b)_{n}}{(c)_{n}} \frac{z^{n}}{n !}
\end{aligned}
$$

dengan $|z|<1, \operatorname{Re}(c)>\operatorname{Re}(b)>0$.

Berikut akan diberikan ulasan singkat tentang distribusi waktu hidup yang didasarkan atas hukum Makeham. Misal $X$ adalah variabel random kontinu yang mengikuti usia hidup seseorang (dari kelahiran sampai kematian). Untuk usia hidup $x$, diberikan percepatan mortalitas yang didasarkan atas hukum Makeham seperti berikut

$$
\mu(x)=A+B c^{x}, \quad x \in \mathbb{R}_{+} .
$$

Bentuk ini sering disebut sebagai hazard rate atau failure rate.

Kemudian berdasarkan hukum Makeham, maka dapat diperoleh fungsi survival dari distribusi Makeham seperti berikut,

$$
\begin{aligned}
S(x) & =\exp \left\{-\int_{0}^{x} \mu(y) d y\right\}=\exp \left\{-\int_{0}^{x}\left(A+B c^{y}\right) d y\right\} \\
& =\exp \left\{-\left[A y+B\left(\frac{c^{y}-1}{\log c}\right)\right]_{0}^{x}\right\} \\
& =\exp \left\{-A x-B\left(\frac{c^{x}-1}{\log c}\right)\right\} \\
& =\exp \left\{-A x-m\left(c^{x}-1\right)\right\}, \text { dengan } m=\frac{B}{\log c}
\end{aligned}
$$

\section{HASIL DAN PEMBAHASAN}

\section{Distribusi Waktu Hidup Yang Akan Datang}

Misal variabel random $X$ memiliki distribusi waktu hidup. Dengan demikian, $x$ adalah usia hidup dari seseorang yang dinotasikan dengan $(x)$. Waktu hidup yang akan datang (future lifetime) dari $(x)$ adalah $X-x$ yang dinotasikan dengan $T(x)$ atau $T_{x}$, atau untuk lebih simpel cukup ditulis dengan notasi $T$; merupakan variabel random yang bergantung pada $(x)$. Berikut akan diberikan cdf dari $T$, yaitu

$$
F(t)=\mathrm{P}(T \leq t), \quad t \in \mathbb{R}_{+} .
$$

Bentuk cdf dari $T$ yang diberikan pada persamaan (2) merupakan peluang $(x)$ meninggal dalam jangka waktu $t$ tahun. Bentuk ini sering dinotasikan dengan ${ }_{t} q_{x}$. Dengan demikian, peluang $(x)$ untuk hidup selama $t$ tahun adalah

$$
{ }_{t} p_{x}=1-{ }_{t} q_{x}=\mathrm{P}(T>t), \quad t \in \mathbb{R}_{+} .
$$

Karena ${ }_{t} q_{x}$ adalah suatu cdf untuk variabel random $T$, maka ${ }_{t} p_{x}$ merupakan ccdf dari $T$, yang dapat ditulis sebagai $\bar{F}_{T}(t)$.

Perhatikan bahwa $\bar{F}_{T}(t)$ merupakan peluang $(x)$ dapat hidup mencapai $x+t$ tahun, sehingga dapat diperoleh hubungan antara fungsi survival $S(x)$ dan ccdf $\bar{F}_{T}(t)$ seperti berikut:

$$
\begin{aligned}
\bar{F}_{T}(t) & =\mathrm{P}(T>t)=\mathrm{P}(X-x>t \mid X>x) \\
& =\mathrm{P}(X>x+t \mid X>x) \\
& =\frac{S(x+t)}{S(x)}, \text { untuk setiap } x, t \in \mathbb{R}_{+}
\end{aligned}
$$

\section{Kombinasi Eksponensial dari Aproksimasi Distribusi Peluang}

\section{a. Kombinasi Eksponensial}

Berikut ini, akan diberikan bentuk umum dari suatu kombinasi ekponensial dengan mendefinisikan sebuah fungsi yang berbentuk

$$
f(t)=\sum_{j=1}^{n} a_{j} \lambda_{j} e^{-\lambda_{j} t} \mathbf{1}_{\{t>0\}}
$$

dimana $\left\{a_{j}\right\},\left\{\lambda_{j}\right\}$ adalah konstan. Fungsi ini adalah fungsi densitas peluang (pdf) jika

(a) $\sum_{j=1}^{n} a_{j}=1$;

(b) $\lambda_{j}>0$, untuk setiap $j$;

(c) $f(x) \geq 0$, untuk setiap $x \geq 0$.

Kondisi (a) dan (b) menyatakan bahwa fungsi $f(\cdot)$ terintegral untuk 1 atas $\mathbb{R}_{+}$, namun tidak untuk kondisi (c). Jika $a_{j}>0$ untuk semua $j$, maka persamaan (4) disebut sebuah mixture of exponentials atau disebut juga sebagai distribusi hiper-eksponensial.

Teorema 1 memperlihatkan kekonvergenan dari barisan variabel random yang mana pdf dari variabel random tersebut merupakan suatu kombinasi eksponensial. Bukti dari Teorema 1 dapat di lihat di Sinay (2010).

\section{Teorema 1.}

(a) Misal $T$ variabel random non negatif. Maka terdapat suatu barisan variabel random $\left\{T_{n}\right\}$ masing-masing dengan suatu pdf yang diberikan oleh suatu kombinasi eksponensial dan sedemikian sehingga $T_{n}$ konvergen dalam distribusi ke T.

(b) Jika distribusi T tidak mempunyai atom, maka

$$
\lim _{n \rightarrow \infty} \sup _{0 \leq t<\infty}\left|F_{T}(t)-F_{T_{n}}(t)\right|=0
$$




\section{b. Polinomial Jacobi Teralihkan}

Pada umumnya, bentuk polinomial Jacobi dapat didefinisikan seperti berikut

$P_{n}^{(\alpha, \beta)}(x)=\frac{(\alpha+1)_{n}}{n !}{ }_{2} F_{1}\left(-n, n+\alpha+\beta+1, \alpha+1 ; \frac{1-x}{2}\right)$, untuk $n=0,1, \ldots$ dan $\alpha, \beta>-1$. Diketahui juga bahwa polinomial Jacobi ortogonal atas interval $[-1,1]$, untuk fungsi bobot

$$
(1-x)^{\alpha}(1+x)^{\beta}
$$

Kemudian bentuk polinomial Jacobi teralihkan (shifted Jacobian polynomials) dapat diturunkan seperti berikut:

$$
\begin{aligned}
R_{n}^{(\alpha, \beta)}(x) & =P_{n}^{(\alpha, \beta)}(2 x-1) \\
& =\frac{(\alpha+1)_{n}}{n !}{ }_{2} F_{1}(-n, n+\alpha+\beta+1, \alpha+1 ; 1-x) \\
& =\sum_{j=0}^{n} \rho_{n j} x^{j},
\end{aligned}
$$

dimana ${ }_{2} F_{1}$ adalah fungsi hipergeometri Gauss dan

$$
\rho_{n j}=\frac{(-1)^{n}(\beta+1)_{n}(-n)_{j}(n+\lambda)_{j}}{(\beta+1)_{j} n ! j !} .
$$

Dengan demikian, polinomial Jacobi teralihkan ortogonal atas $[0,1]$, dengan fungsi bobotnya adalah

$$
w^{(\alpha, \beta)}(x)=(1-x)^{\alpha} x^{\beta} .
$$

Sifat-sifat dari polinomial Jacobi teralihkan dapat diberikan untuk suatu fungsi $\phi(\cdot)$ yang terdefinisi atas $(0,1)$ (termasuk semua fungsi kontinu dan terbatas) sedemikan sehinga,

$$
\begin{gathered}
w^{(\alpha, \beta)}(x)=(1-x)^{\alpha} x^{\beta}, \\
c_{n}=\frac{1}{h_{n}} \int_{0}^{1} \phi(x)(1-x)^{\alpha} x^{\beta} R_{n}^{(\alpha, \beta)}(x) d x, \\
h_{n}=\int_{0}^{1}(1-x)^{\alpha} x^{\beta}\left[R_{n}^{(\alpha, \beta)}(x)\right]^{2} d x \\
=\frac{\Gamma(n+\alpha+1) \Gamma(n+\beta+1)}{(2 n+\lambda) n ! \Gamma(n+\lambda)}
\end{gathered}
$$

\section{c. Aproksimasi Distribusi Waktu Hidup Yang Akan Datang}

Berdasarkan teori shifted Jacobi polynomials yang diberikan pada bagian sebelumnya, maka teori tersebut dapat diterapkan ke dalam suatu distribusi peluang atas $\mathbb{R}_{+}$dengan cara seperti berikut ini.

Misal $F(t)$ adalah cdf, dan misal $\bar{F}(t)=1-F(t)$ $=\mathrm{P}(T>t) \cdot \bar{F}(t)$ merupakan ccdf (komplemen cdf). $\bar{F}(t)$ sering disebut juga sebagai fungsi survival. Jika $\bar{F}(0)=1 \quad$ dan $\quad \bar{F}(\infty)=1$, untuk $0 \leq t<\infty$. Misal $T$ menyatakan waktu sampai kematian dari usia hidup $x$, maka $\bar{F}(t)={ }_{t} p_{x}$.
Diketahui bahwa $r>0$,

$$
g(x)=\bar{F}\left\{-\frac{1}{r} \log (x)\right\}, 0<x \leq 1, \quad g(0)=0 .
$$

Pemetaan yang terjadi dari bentuk ini merupakan pemetaan $[0, \infty)$ pada $(0,1]$, yang mana $t=0$ berkorespondensi dengan $x=1$, dan $t \rightarrow \infty$ berkorespondensi dengan $x \rightarrow 0+$. Diketahui juga bahwa $\bar{F}(\infty)=0$, maka dapat diperoleh sedemikian rupa sehingga $g(0)=0$.

Misal parameter-parameter $\alpha, \beta, p$ dan $\left\{b_{k}\right\}$ diketahui sedemikian sehingga, dengan menerapkan shifted Jacobi polynomials dapat diperoleh

$$
g(x)=x^{p} \sum_{k=0}^{\infty} b_{k} R_{k}^{(\alpha, \beta)}(x), \quad 0<x \leq 1 .
$$

Ekuivalen dengan

$$
\begin{aligned}
\bar{F}(t)= & g\left(e^{-r t}\right) \\
& =e^{-p r t} \sum_{k=0}^{\infty} b_{k} \sum_{j} \rho_{k j} e^{-j r t} \\
& =\sum_{j}\left(\sum_{k=0}^{\infty} b_{k} \rho_{k j}\right) e^{-(j+p) r t} .
\end{aligned}
$$

Bentuk di atas memiliki kesamaan dengan bentuk (4), jika $\lambda_{j}=(j+p) r$, untuk $j=0,1,2, \ldots$. Jika $p>0$, suatu kombinasi eksponensial dapat diperoleh dengan cara pemotongan jumlahan dari deret di atas. Berdasarkan bentuk dari deret yang diberikan di atas, maka konstanta $\left\{b_{k}\right\}$ dapat ditemukan seperti berikut:

$$
\begin{aligned}
b_{k} & =\frac{1}{h_{k}} \int_{0}^{1} x^{-p} g(x) R_{k}^{(\alpha, \beta)}(x)(1-x)^{\alpha} x^{\beta} d x \\
& =\frac{r}{h_{k}} \int_{0}^{\infty} e^{-(\beta-p+1) r t}\left(1-e^{-r t}\right)^{\alpha} R_{k}^{(\alpha, \beta)}\left(e^{-r t}\right) \bar{F}(t) d t .
\end{aligned}
$$

Dengan demikian, bentuk (5) merupakan kombinasi dari bentuk

$$
\int_{0}^{\infty} e^{-(\beta-p+j+1) r t}\left(1-e^{-r t}\right)^{\alpha} \bar{F}(t) d t, \quad j=0,1, \ldots, k
$$

Jika $\alpha=0$, maka dapat diperoleh

$$
\int_{0}^{\infty} e^{-s t} \bar{F}(t) d t=-\frac{1}{s} \int_{0}^{\infty} \bar{F}(t) d\left(e^{-s t}\right)=\frac{1}{s}\left[1-\mathrm{E} e^{-s t}\right],
$$

dengan $s>0$

Hal ini berarti, konstanta $\left\{b_{k}\right\}$ dapat diperoleh dengan menggunakan transformasi Laplace dari distribusi $T$.

Teorema berikut ini merupakan konsekuensi langsung dari shifted Jacobian polynomials.

Teorema 2. Misal $\alpha, \beta>-1, \bar{F}(\cdot)$ kontinu atas $[0, \infty)$ dan diberikan fungsi beriku ini.

$$
e^{p r t} \bar{F}(t)
$$


yang memiliki sebuah limit yang berhingga untuk $t$ menuju tak hingga, untuk beberapa $p \in \mathbb{R}$ (hal ini selalu benar di mana $p \leq 0$ ). Maka berlaku

$$
\bar{F}(t)=e^{-p r t} \sum_{k=0}^{\infty} b_{k} R_{k}^{(\alpha, \beta)}\left(e^{-r t}\right)
$$

Untuk setiap $t \in(0, \infty)$ dan konvergen seragam atas setiap interval $[a, b]$, untuk $0<a<b<\infty$.

Bukti lihat Sinay (2010)

Tidak semua distribusi terkondisi dalam Teorema 2. Hasil dalam teorema berikut tidak membutuhkan asumsi ini.

Teorema 3. Misal $\alpha, \beta>-1$ dan untuk beberapa $p \in \mathbb{R}$ dan $r>0$

$$
\int_{0}^{\infty} e^{-(\beta+1-2 p) r t}\left(1-e^{-r t}\right)^{\alpha} \bar{F}(t)^{2} d t<\infty
$$

(ini selalu benar jika $p<\frac{\beta+1}{2}$ ). Maka

$$
\begin{array}{r}
\lim _{N \rightarrow \infty} \int_{0}^{\infty}\left(\left[\bar{F}(t)-e^{-p r t} \sum_{k=0}^{N} b_{k} R_{k}^{(\alpha, \beta)}\left(e^{-r t}\right)\right]^{2}\right. \\
\left.e^{-(\beta+1-2 p) r t}\left(1-e^{-r t}\right)^{\alpha}\right) d t=0
\end{array}
$$

Bukti lihat Sinay (2010).

Pemotongan jumlahan dari deret yang diperoleh dengan menggunakan metode ini bukanlah fungsi distribusi yang sebenarnya. Ini merupakan suatu aproksimasi dari bentuk ccdf distribusi $T$. Fungsi yang diperoleh dari metode ini, bisa lebih kecil dari 0 atau lebih besar dari 1, atau fungsi tersebut mungkin saja turun pada beberapa interval.

\section{Implementasi Numerik}

Hasil-hasil yang diperoleh pada bagian ini didasarkan atas hukum Makeham seperti yang diberikan pada persamaan (1), dengan menggunakan asumsi parameter-parameter seperti berikut:

$$
A=0.0007 ; \quad B=5 \times 10^{-5} ; \quad c=10^{0.04},
$$

yang mengikuti Bowers et al (1997).

\section{a. Aproksimasi Distribusi Waktu Hidup Yang Akan \\ Datang}

Hasil aproksimasi yang diperoleh pada bagian ini menggunakan persamaan (6), dengan menggunakan parameter-parameter berikut $\alpha=\beta=0, p=0.2, r=0.08$.

Berdasarkan persamaan (3), maka dapat diperoleh

$$
\begin{aligned}
\bar{F}(t) & =\frac{S(x+t)}{S(x)} \\
& =e^{1.09648^{x}\left[0.0005429-0.0005429\left(1.09648^{t}\right)\right]-0.0007 t}
\end{aligned}
$$

dengan $t \in \mathbb{R}_{+}$. Hasil ini dapat diterapkan pada persamaan (6) untuk usia hidup $x=30$ dan $x=65$, dengan $N=18$. Hasil secara visual dapat dilihat pada Gambar 1 .
Dengan demikian, tingkat ketelitian pada saat $N=18$ cukup baik (lihat Tabel 1).

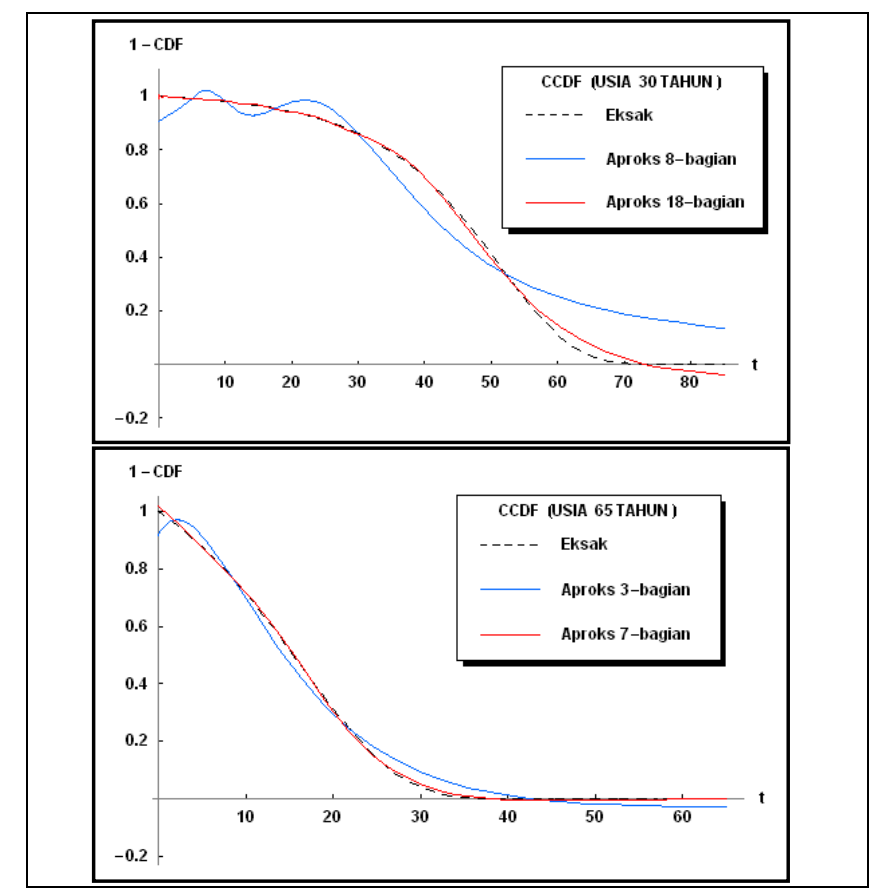

Gambar 1. Distribusi waktu hidup yang akan datang

Dari Gambar 1, dapat dilihat bahwa aproksimasi yang digunakan untuk mengaproksimasi distribusi waktu hidup yang akan datang sangat akurat. Dengan demikian, hasil aproksimasi sangat akurat untuk diterapkan.

Untuk melihat tingkat ketelitian dari hasil aproksimasi dari distribusi waktu hidup yang akan datang untuk beberapa $N$ yang berbeda dapat dilihat pada Tabel 1, dimana tingkat ketelitian semakin baik untuk usia hidup 65 tahun, dan untuk nilai yang semakin besar.

Tabel 1

Estimasi tingkat ketelitian

\begin{tabular}{cll}
\hline \multirow{2}{*}{} & \multicolumn{2}{c}{$\left\|\boldsymbol{F}-\widehat{\boldsymbol{F}}_{\boldsymbol{N}}\right\|$} \\
\cline { 2 - 3 } & \multicolumn{1}{c}{$(\mathbf{3 0})$} & \multicolumn{1}{c}{$(\mathbf{6 5})$} \\
\hline \hline $\mathbf{3}$ & 0.41 & 0.082 \\
$\mathbf{5}$ & 0.3 & 0.043 \\
$\mathbf{7}$ & 0.198 & 0.0198 \\
$\mathbf{1 0}$ & 0.0798 & 0.0065 \\
$\mathbf{1 8}$ & 0.043 & 0.001 \\
\hline
\end{tabular}

\section{KESIMPULAN}

Berdasarkan hasil-hasil penelitian yang diberikan dalam penulisan ini, maka dapat disimpulkan bahwa Bentuk aproksimasi ccdf (fungsi survival) dari distribusi waktu hidup yang akan datang adalah

$$
\bar{F}(t)=e^{-p r t} \sum_{k=0}^{\infty} b_{k} R_{k}^{(\alpha, \beta)}\left(e^{-r t}\right),
$$

yaitu dengan melakukan pemotongan terhadap jumlahan dari deret tersebut. Misal pemotongan deret di atas dalam 
$N$ bagian, maka hasil dari aproksimasi tersebut dapat dinyatakan dalam bentuk

$$
\bar{F}(t) \approx \sum_{j=0}^{N} c_{j} e^{-\lambda_{j} t}
$$

dengan $\lambda_{j}=(j+p) r, j=0,1, \ldots, N$.

Dengan demikian, bentuk aproksimasi yang dihasilkan adalah suatu bentuk kombinasi eksponensial. Tingkat ketelitiannya semakin membaik jika $N$ semakin meningkat.

Hasil-hasil yang diberikan dalam penulisan ini dapat digunakan untuk penghitungan nilai-nilai anuitas hidup kontinu (bentuk eksak) maupun anuitas hidup stokastik. Hal ini dikarenakan oleh hasil yang didapat secara numerik sangat akurat.

\section{DAFTAR PUSTAKA}

Bowers, N. L. Jr., Gerber, H. U., Hickman, J. C., Jones, D. A., dan Nesbitt, C. J., 1997, Actuarial Mathematics. edisi kedua, Society of Actuaries, Schaumburg, IL.

Dufresne, D., 2006, Fitting Combinations of Exponentials to Probability Distributions, To Appear in Applied Stochastic Models in Business and Industry.

Dufresne, D., 2007, Stochastic Life Annuities, North American Actuarial Journal.

Sinay, L. J., 2010, Anuitas Hidup yang didasarkan atas Kombinasi Eksponensial dari Aproksimasi Distribusi Waktu Hidup Yang Akan Datang, Tesis pada Program Studi S2 Matematika Fakultas MIPA, Universitas Gadjah Mada, Yogyakarta. 